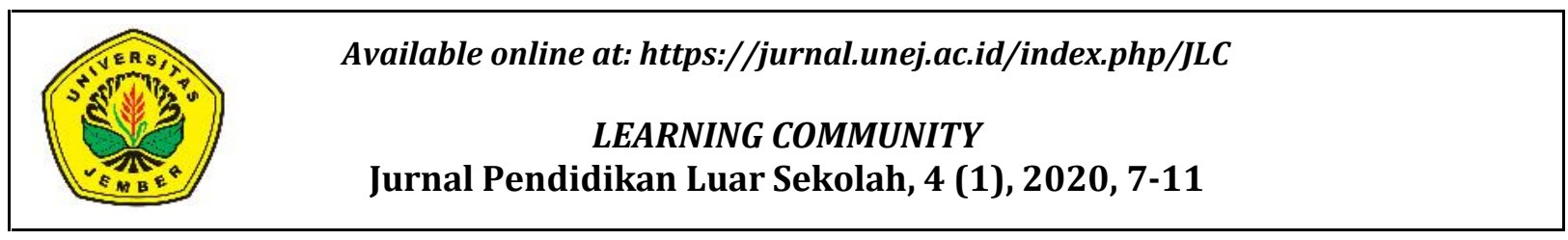

\title{
Hubungan Pemanfaatan Kartu Pintar dengan Program Keaksaraan Fungsional di PKBM Al-Muttaqin Kecamatan Patrang Kabupaten Jember
}

\author{
Ririn Faulina, Deditiani Tri Indrianti, Muhammad Irfan Hilmi \\ Pendidikan Luar Sekolah, Universitas Jember. Jl. Kalimantan No. 37, Tegal Boto, Jember 62811, Indonesia \\ Email : ririnpaulina1@gmail.com
}

\begin{abstract}
Abstrak
Media merupakan salah satu komponen penting yang mendukung keberhasilan program keaksaraan fungsional. Penggunaan media harus disesuaikan dengan kebutuhan dan minat warga belajar agar dapat membantu pencapaian tujuan pembelajaran. Tujuan penelitian ini untuk mengetahui hubungan pemanfaatan kartu pintar dengan program keaksaraan fungsional di PKBM Al-Muttaqin Kecamatan Patrang Kabupaten Jember. Metode penelitian menggunakan jenis penelitian korelasional dengan pendekatan kuantitatif. Teknik pengambilan data dilakukan dengan penyebaran angket kepada responden dan dokumentasi. Analisis data dilakukan mengggunakan teknik analisis korelasi product moment. Hasil analisis diketahui adanya hubungan antara pemanfaatan kartu pintar dengan program keaksaraan fungsional di PKBM AlMuttaqin Kecamatan Patrang Kabupaten Jember. Hasil tersebut dibuktikan dengan hasil perhitungan uji korelasi product moment menggunakan aplikasi SPSS versi 22 yang menunjukkan nilai sebesar 0,697 dengan taraf signifikansi 95\% yang berarti hubungan kuat. Kesimpulan penelitian ini adalah $\mathrm{Ha}$ diterima yang berarti ada hubungan antara pemanfaatan kartu pintar dengan program keaksaraan fungsional di PKBM Al-Muttaqin Kecamatan Patrang Kabupaten Jember.
\end{abstract}

Kata Kunci: media pembelajaran, kartu pintar, keaksaraan fungsional

\section{The Correlation of Utilizing Smart Card with Fuctional Literacy Program at PKBM Al-Muttaqin Patrang Jember}

\begin{abstract}
Media is one of the important components that supports the success of functional literacy program. The use of media should be in accordance with needs and interests of the society so that it can help achieve the learning objectives. This research was intended to find out the correlation between the utilization of smart card and functional literacy program at Al-Muttaqin PKBM, Patrang Sub-district, Jember Regency. This research used correlational method with quantitative approach. The data collection techique was done by distributing questionnaires to the respondents and documentations. The data analysis was done by using product moment correlation analysis technique. From the analysis results, it was known that there was a correlation between the utilization of smart card and functional literacy program at Al-Muttaqin PKBM, Patrang Subdistrict, Jember Regency. It was confirmed by the results of the product moment correlation test calculations by using SPSS version 22 application which showed a value of 0.697 with a significance level of 95\% which means a strong correlation. Thus, we can conclude that Ha was accepted, which means that there was a correlation between the utilization of smart card and functional literacy program at Al-Muttaqin PKBM, Patrang Sub-district, Jember Regency.
\end{abstract}

Keywords: learning media, smart card, functional literacy. 


\section{Learning Community: Jurnal Pendidikan Luar Sekolah, 4 (1), Maret 2020 - 8 \\ Ririn Faulina}

\section{PENDAHULUAN}

Salah satu komponen pendukung keberhasilan pembelajaran adalah media belajar. Menurut Pane (2017:349), media berfungsi sebagai alat bantu untuk memperlancar penyelenggaraan pembelajaran agar lebih efisien dan efektif dalam mencapai tujuan pembelajaran. Pada proses pembelajaran keaksaraan fungsional, media belajar menjadi salah satu hal yang penting dan sangat diperlukan. Media belajar merupakan sarana penyalur pesan atau informasi yang dapat digunakan oleh tutor untuk menyampaikan infromasi kepada warga belajar. Media belajar juga dapat membantu warga belajar untuk memahami materi yang disampaikan oleh tutor dengan lebih baik. Sehingga penggunaan media belajar yang tepat dapat membantu tersampaikannya informasi dengan lebih baik dan membantu pencapaian tujuan pembelajaran.

Sejauh ini banyak penyelenggara program keaksaraan fungsional, baik oleh lembaga-lembaga maupun komunitas. Akan tetapi, tidak semua penyelenggara program keaksaraan fungsional memperhatikan halhal tersebut. Kebanyakan pembelajaran keaksaraan fungsional menggunakan metode ceramah dan hanya menggunakan media buku modul keaksaraan. Sujarwo (2012:4-5) mengatakan bahwa tutor ataupun penyelenggara program keaksaraan fungsional dituntut untuk mampu merancang, menyusun atau mengembangkan media yang digunakan dalam proses pembelajaran yang dikelolanya. Hal tersebut bertujuan agar pembelajaran lebih variatif dan tidak monoton.

Warga belajar program keaksaraan fungsional merupakan orang dewasa yang mengalami putus sekolah atau drop out sekolah. Menurut Sujarwo (2012:2) berdasarkan prinsip pembelajaran partisipatif dan andragogis, maka media pembelajaran yang digunakan hendaknya mengikuti alur atau siklus belajar berdasarkan pengalaman. Mengingat bahwa orang dewasa membutuhkan pembelajaran yang praktis dan langsung dapat diterapkan dalam kehidupannya.
Media belajar sendiri dibagi menjadi beberapa macam, salah satunya adalah media berbasis visual (image) atau perumpamaan. Menurut Arsyad (2017:89) media visual memegang peranan yang sangat penting dalam proses belajar, karena dapat memperlancar pemahaman dan memperkuat ingatan warga belajar. Salah satu contoh dari media belajar visual adalah kartu pintar. Kartu pintar merupakan salah satu jenis media visual sederhana yang dapat digunakan dalam proses pembelajaran, termasuk pada pembelajaran keaksaraan fungsional. Kartu pintar berisi gambar, huruf, kata, dan kalimat.

\section{METODE}

Penelitian ini dilakukan menggunakan jenis penelitian korelasional dengan pendekatan kuantitatif. Tempat penelitian dilaksanakan di PKBM Al-Muttaqin Kecamatan Patrang Kabupaten Jember. Teknik penentuan tempat penelitian menggunakan teknik purposive area.

Populasi penelitian ini sebanyak 311 warga belajar. Menurut Arikunto (1986); dalam Masyhud (2016: 94) jika jumlah subyek besar atau banyak, dapat diambil sampel sebanyak $10-15 \%$ atau $20-25 \%$ atau lebih, bergantung pada kemampuan peneliti, luasnya wilayah dan besar-kecilnya resiko yang ditanggung peneliti. Sedangkan menurut Roscoe (1982:253); dalam Sugiyono (2016:91) mengatakan bahwa jika sampel pada sebuah penelitian antara 30-500 maka layak untuk dilakukan penelitian, termasuk penelitian kuantitaif korelasional. Oleh karena itu dalam penelitian ini peneliti mengambil sampel sebanyak $10 \%$ secara acak karena populasi sama-sama mengikuti program keaksaraan fungsional dan menggunakan media kartu pintar, sehingga diketahui sebanyak 31 warga belajar terpilih sebagai sampel. Penentuan sampel pada penelitian ini menggunakan teknik cluster sampling. Adapun yang menjadi responden penelitian yakni warga belajar program keaksaraan fungsional tahun angkatan penyelenggaraan 2012, 2013, dan 2014. Pengumpulan data penelitian dilakukan dengan cara penyebaran angket kepada responden dan dokumentasi. Pada data yang telah diperoleh kemudian dilakukan coding 


\section{Learning Community: Jurnal Pendidikan Luar Sekolah, 4 (1), Maret 2020 - 9}

Ririn Faulina

dan scoring untuk memudahkan proses analisis. Analisis data dilakukan menggunakan rumus korelasi product moment dan dianalisis menggunakan aplikasi SPSS (Statistical Package Social Science) versi 22 agar mendapat hasil yang akurat.

\section{HASIL DAN PEMBAHASAN}

Adapun hasil dari hubungan pemanfaatan kartu pintar (X) dengan program keaksaraan fungsional di PKBM Al-Muttaqin Kecamatan Patrang Kabupaten Jember (Y) diperoleh nilai rhitung sebesar 0,697. Pada taraf signifikansi 95\% diperoleh nilai sebesar 0,000 yaitu lebih kecil dari 0,05. Berdasarkan hasil tersebut maka dapat disimpulkan bahwa ada hubungan antara pemanfaatan kartu pintar dengan program keaksaraan fungsional di PKBM Al- Muttaqin Kecamatan Patrang Kabupaten Jember. Dilihat dari tabel interpretasi nilai korelasi, maka nilai 0,697 adalah kategori kuat.

Hasil hubungan dari indikator pertama pada penelitian ini yaitu hubungan pemanfaatan kartu pintar sebagai fungsi kognitif dengan konteks lokal partisipatif pada materi pembelajaran diperoleh nilai rhitung sebesar 0,398. Pada taraf signifikansi 95\% diperoleh nilai sebesar 0,027 yaitu lebih kecil dari 0,05. Dengan hasil tersebut berarti signifikan sehingga Ha diterima dan Ho ditolak. Berdasarkan hasil tersebut maka dapat disimpulkan bahwa ada hubungan antara pemanfaatan kartu pintar fungsi kognitif dengan konteks lokal partisipatif pada materi pembelajaran Dilihat dari tabel interpretasi nilai korelasi, maka nilai 0,398 adalah kategori rendah.

Hasil hubungan dari indikator kedua pada penelitian ini yaitu hubungan pemanfaatan kartu pintar sebagai fungsi kognitif dengan desain lokal pada materi pembelajaran diperoleh nilai rhitung sebesar 0,475. Pada taraf signifikansi 95\% diperoleh nilai sebesar 0,007 yaitu lebih kecil dari 0,05. Dengan hasil tersebut berarti signifikan sehingga Ha diterima dan Ho ditolak. Berdasarkan hasil tersebut maka dapat disimpulkan bahwa ada hubungan antara pemanfaatan kartu pintar sebagai fungsi kognitif dengan desain lokal pada materi pembelajaran. Dilihat dari tabel interpretasi nilai korelasi, maka nilai 0,475 adalah kategori sedang.

Hasil hubungan dari indikator ketiga pada penelitian ini yaitu hubungan pemanfaatan kartu pintar sebagai fungsi kompensatoris dengan konteks lokal pada materi pembelajaran diperoleh nilai rhitung sebesar 0,637. Pada taraf signifikansi 95\% diperoleh nilai sebesar 0,000 yaitu lebih kecil dari 0,05. Dengan hasil tersebut berarti signifikan sehingga $\mathrm{Ha}$ diterima dan $\mathrm{Ho}$ ditolak. Berdasarkan hasil tersebut maka dapat disimpulkan bahwa ada hubungan antara pemanfaatan kartu pintar sebagai fungsi kompensatoris dengan konteks lokal pada materi pembelajaran. Dilihat dari tabel interpretasi nilai korelasi, maka nilai 0,637 ialah kategori kuat,

Hasil hubungan dari indikator keempat pada penelitian ini yaitu hubungan pemanfaatan kartu pintar sebagai fungsi kompensatoris dengan desain lokal pada materi pemebelajaran diperoleh nilai rhitung sebesar 0,692. Pada taraf signifikansi 95\% diperoleh nilai sebesar 0,000 yaitu lebih kecil dari 0,05. Dengan hasil tersebut berarti signifikan sehingga $\mathrm{Ha}$ diterima dan $\mathrm{Ho}$ ditolak. Berdasarkan hasil tersebut maka dapat disimpulkan bahwa ada hubungan antara antara pemanfaatan kartu pintar sebagai fungsi kompensatoris dengan desain lokal pada materi pembelajaran. Dilihat dari tabel interpretasi nilai korelasi, maka nilai 0,692 adalah kategori kuat.

Berdasarkan penyajian dan interpretasi yang telah dipaparkan pada bagian sebelumnya, dapat dilakukan analisis data penelitian. Berdasarkan hasil perhitungan pada hubungan antara pemanfaatan kartu pintar dengan program keaksaraan fungsional di PKBM Al-Muttaqin Kecamatan Patrang Kabupaten Jember yang menunjukkan hasil kuat yaitu 0,697 dapat dipengaruhi oleh beberapa faktor seperti media belajar yang digunakan dalam proses pembelajaran telah sesuai atau tepat. Menurut Hamalik (1942:78) dalam Arsyad (2017:20) bahwa media belajar dapat membangkitkan motivasi dan minat warga belajar. Selain itu juga dapat membantu warga belajar meningkatkan pemahaman, menyajikan data dengan menarik dan terpercaya, memudahkan penafsiran data dan mmadatkan informasi. Mengetahui akan 


\section{Learning Community: Jurnal Pendidikan Luar Sekolah, 4 (1), Maret 2020 - 10}

Ririn Faulina

hal tersebut maka media belajar yang digunakan dalam pembelajaran program keaksaraan fungsional di PKBM Al-Muttaqin Kecamatan Patrang Kabupaten Jember telah tepat dan sesuai dengan karakteristik, kebutuhan, dan minat warga belajar.

Berdasarkan hasil perhitungan pada hubungan antara pemanfaatan kartu pintar sebagai fungsi kognitif dengan konteks lokal pada materi pembelajaran yang menunjukkan hasil rendah yaitu 0,398 dapat dipengaruhi oleh faktor-faktor lain, seperti kurang optimalnya penggunaan atau pemanfaatan kartu pintar sebagai media pembelajaran dalam hal peningkatan pengetahuan dari warga belajar, atau informasi yang disampaikan pada kartu pintar kurang mengarah pada pengalamanpengalaman dari warga belajar. Menurut Arsyad (2017:74) media pembelajaran yang dalam hal ini ialah kartu pintar harus disesuaikan dengan tujuan pembelajaran. Informasi yang disampaikan pada kartu pintar sebagai fungsi kognitif berarti harus mengacu pada ranah kognitif. Hal tersebut dapat digambarkan pada tugas warga belajar untuk menghafal atau atau tugas-tugas yang melibatkan pemahaman. Mengetahui akan hal tersebut maka tutor program keaksaraan fungsional di PKBM Al- Muttaqin Kecamatan Patrang Kabupaten Jember perlu mengetahui hal-hal tersebut dan perlunya dilakukan evaluasi terhadap pemilihan materi serta penggunaan dari media kartu pintar sebagai fungsi kognitif dalam pembelajaran.

Pada hubungan pemanfaatan kartu pintar sebagai fungsi kognitif dengan desain lokal pada materi pembelajaran yang menunjukkan hasil sedang yaitu 0,475 dapat dipengaruhi oleh beberapa faktor, seperti proses penyampaian materi atau informasi oleh tutor kepada warga belajar kurang memperhatikan kondisi warga belajar. Sehingga jika kondisi warga belajar telah diperhatikan dengan baik maka akan menunjukkan hubungan dengan tingkat yang tinggi. Menurut Maf'ullah (2013:3) dalam proses belajar dan pengembangan program keaksaraan fungsional hendaknya memperhatikan karakteristik warga belajar. Warga belajar yang turut belajar dalam proses pembelajaran memiliki perbedaan satu sama lain. Warga belajar sebagai orang dewasa yang memiliki pengalaman beragam yang lebih banyak dibandingkan dengan anak-anak. Lebih lanjut, Maf'ullah menyatakan bahwa orang dewasa akan merasa dihargai ketika pembelajaran yang diikuti mengacu pada proses pemecahan masalah, bertukar informasi, sesuai dengan pengalaman yang telah mereka lewati dan tidak terkesan mentutori. Mengetahui akan hal tersebut maka materi yang disampaikan pada kartu pintar sebagai fungsi kognitif di PKBM Al- Muttaqin Kecamatan Patrang Kabupaten Jember hendaknya disesuaikan berdasarkan kebutuhan dari warga belajar.

Pada hubungan pemanfaatan kartu pintar sebagai fungsi kompensatoris dengan konteks lokal pada materi pembelajaran yang menunjukkan hasil tinggi yaitu 0,637 dapat dipengaruhi oleh beberapa faktor, seperti prinsip-prinsip yang diterapkan dalam media kartu pintar sebagai fungsi kompensatoris ialah sudah tepat. Menurut Raharjo (Mahnun, 2012:29) menyatakan bahwa dalam pemilihan media hendaknya diperhatikan prinsipprinsip, seperti kejelasan maksud menggunakan media tersebut. Jika tingkat hubungan yang tinggi antara pemanfaatan kartu pintar sebagai fungsi kompensatoris dengan konteks lokal pada materi pembelajaran di PKBM Al-Muttaqin Kecamatan Patrang Kabupaten Jember menunjukkan hasil tinggi maka materi yang terdapat pada kartu pintar ialah telah tepat dengan tujuan pembelajaran. Sehingga fungsi kompensatoris dari kartu pintar yakni membantu warga belajar untuk menyusun atau menulis kembali materi atau informasi yang disajikan secara tekstual maupun verbal telah dapat diterapkan dengan baik oleh warga belajar.

Pada hubungan pemanfaatan kartu pintar sebagai fungsi kompensatoris dengan desain lokal pada materi pembelajaran yang menunjukkan hasil tinggi yaitu 0,692 dapat dipengaruhi oleh beberapa faktor, seperti penyusunan kurikulum telah tepat dengan kondisi warga belajar. Menurut Maf'ullah (2013: 3) bahwa rancangan kegiatan belajar (kurikulum) yang telah disusun oleh tutor atas dasar kebutuhan dan minat dari warga belajar harus fleksibel, 


\section{Learning Community: Jurnal Pendidikan Luar Sekolah, 4 (1), Maret 2020 - 11 Ririn Faulina}

sudah dimodifikasi, diganti, ditambah dengan disesuaikan dengan kebutuhan dan minat dari warga belajar. Hal tersebut bertujuan agar tujuan pembelajaran dapat dicapai dengan maksimal, dan materi atau ilmu yang telah diperoleh oleh warga belajar langsung dapat diterapkan dalam kehidupan sehari-hari. Sehingga jika dilihat dari tingkat hubungan yang tinggi antara pemanfaatan kartu pintar sebagai fungsi kompensatoris dengan desain lokal pada materi pembelajaran di PKBM Al-Muttaqin Kecamatan Patrang Kabupaten Jember ialah karena tutor telah merancang dan memodifikasi kurikulum tepat sesuai dengan kondisi lokal warga belajar.

\section{SIMPULAN}

Berdasarkan hasil analisis data pada bab sebelumnya maka dapat disimpulkan bahwa ada hubungan yang kuat antara pemanfaatan kartu pintar dengan program keaksaraan fungsional di PKBM AlMuttaqin Kecamatan Patrang Kabupaten Jember. Hal tersebut dibuktikan dengan hasil nilai rhitung lebih besar dari rtabel. Dengan hasil tersebut berarti signifikan sehingga Ha yang berbunyi ada hubungan antara pemanfaatan kartu pintar dengan program keaksaraan fungsional di PKBM AlMuttaqin Kecamatan Patrang Kabupaten Jember.

\section{DAFTAR PUSTAKA}

Arsyad, A. 2017. Media Pembelajaran. Edisi Revisi. Jakarta: Rajawali Pers.

Maf'ullah, S. 2013. Analisis Karakteristik Warga Belajar Dalam Pengembangan Program Pembelajaran Keaksaraan fungsional di PKBM Sanggar Belajar Yalatif Diwek Jombang. Jurnal UNESA. 1-11.

Mahnun, N. 2012. Media Pembelajaran (Kajian terhadap Langkah-langkah Pemilihan Media dan Implementasinya dalam Pembelajaran). Jurnal Pemikiran Islam. 37(1): 27-33.

Masyhud, S. 2016. Metode Penelitian Pendidikan. Edisi ke 5. Jember: Lembaga Pengembangan Manajemen dan Profesi Kependidikan (LPMPK).

Mas'udi. 2014. Pengaruh Komitmen dan Motivasi Berprestasi Terhadap Kinerja Guru SMA Negeri 56 Jakarta. Jurnal MIX. 4(2): 260-269.

Pane, A. 2017. Belajar dan Pembelajaran. Jurnal Kajian Ilmu-ilmu Keislaman 2(3): 333-352

Sugiyono. 2016. Metode Penelitian Kuantitatif, Kualitatif, dan R \& D. Bandung: Alfabeta.

Sujarwo. 2012. Pengembangan Media Pembelajaran Keaksaraan. Jurnal UNY. 1-12. 